\title{
Lifestyle Intervention Programs for Adults at High- Risk for Type 2 Diabetes: A Platform to Reach High-Risk Children?
}

\author{
Maya Venkataramani, MD, MPH, Tina L. Cheng, MD, MHS, \\ Hsin-Chieh Yeh, PhD, and Nisa M. Maruthur, MD, MHS
}

Introduction: Children of adults eligible for the National Diabetes Prevention Program (DPP) lifestyle intervention may themselves be high risk for type 2 diabetes development, and high-risk children may be reached through programs that target high-risk adults. To understand the potential multigenerational impact of family-oriented diabetes prevention programming, we explored the correlation between parental eligibility for the National DPP program and child weight status by using nationally representative data.

Methods: We analyzed data from the National Health Interview Survey from 2016 and 2017, focusing on children ages 12 through 17 years of age for whom body mass index (BMI) data were available and who could be linked to 1 sample parent. We explored the association between parent and child weight status and parental DPP eligibility and child weight status using $\chi^{2}$ analyses.

Results: Our final sample consisted of 3,905 (unweighted) children, linked to either a mother or father. A total of $25.8 \%$ of children were overweight or obese; $68.1 \%$ of linked parents were overweight or obese, and child and parent weight status were correlated (Pearson's $\chi^{2}, P<.001$ ). A total of $9.5 \%$ of parents were likely eligible to participate in the National DPP. Parental program eligibility was positively correlated with child overweight/obese status $\left(\chi^{2}, P<.001\right)$; over one-third of children with eligible parents were themselves overweight/obese.

Discussion: In this nationally representative sample, parental BMI and child BMI categories were positively correlated, as was parental eligibility for diabetes prevention programming and child BMI. This highlights the potential of leveraging the national platform for adult diabetes prevention to reach high-risk children through family-oriented programming. (J Am Board Fam Med 2019;32:596-600.)

Keywords: Body Mass Index, Chronic Disease, Pediatric Obesity, Overweight, Parents, Prediabetic State, Surveys and Questionnaires, Type 2 Diabetes Mellitus

The prevalence of type 2 diabetes is increasing among children in the United States, ${ }^{1,2}$ and there is a pressing need to address lifestyle-related risk factors among high-risk children. Weight status is

This article was externally peer reviewed.

Submitted 29 October 2018; revised 12 February 2019; accepted 17 February 2019.

From Division of General Internal Medicine, Johns Hopkins University School of Medicine, Baltimore, MD (MV, H-CY, NMM); Department of Pediatrics, Johns Hopkins University School of Medicine, Baltimore, MD (MV, TC); Welch Center for Prevention, Epidemiology and Clinical Research, Baltimore, MD (MV, H-CY, NMM).

Funding: none.

Conflict of interest: Dr. Maruthur is a coinventor of technology related to diabetes prevention. This technology is not under study specifically in this publication. Under a perhaps the strongest modifiable risk factor for diabetes development ${ }^{3}$; loss of weight among overweight and obese individuals can prevent or delay type 2 diabetes development. ${ }^{4}$ Child obesity is also a risk factor for multiple other comorbidities, in-

license agreement between Johns Hopkins Health Care Solutions and the Johns Hopkins University, Dr. Maruthur and the University are entitled to royalty distributions related to this technology. This arrangement has been reviewed and approved by the Johns Hopkins University in accordance with its conflict of interest policies.

Corresponding author: Maya Venkataramani, MD, MPH, Division of General Internal Medicine, Johns Hopkins University School of Medicine, Baltimore, MD 21205 (E-mail: mvenkat2@jhmi.edu). 
cluding cardiovascular comorbidities such as hypertension and dyslipidemia. ${ }^{5}$

Some studies have revealed a correlation between parental and child body mass index (BMI) or obesity status. ${ }^{6}$ Evidence that this correlation has strengthened over time indicates that shared genetic predisposition and shared environmental risk factors contribute to child-parental weight status concordance. ${ }^{7}$ Clustering of such modifiable and nonmodifiable risk factors in families highlights the potential for multigenerational approaches to identify high-risk individuals and prevent disease via evidence-based interventions. ${ }^{8}$

The national focus to identify and intervene on the lifestyle of adults at high risk for type 2 diabetes development, led by the Centers for Disease Control and Prevention's National Diabetes Prevention Program (National DPP), could provide a unique platform to identify and intervene on children at high risk for type 2 diabetes and other lifestyleassociated conditions. Adults are eligible for the National DPP's lifestyle change program based on meeting minimum BMI criteria and possessing additional risk factors (prediabetes, history of gestational diabetes, or high risk assessment scores that take into account factors such as family history). ${ }^{9}$ The program enables its adult participants to achieve 5\% weight loss and perform 150 minutes/ week of moderate intensity physical activity through lifestyle change. The program does not specifically intervene on the lifestyle-related behaviors of household members.

Children of adults eligible for the National DPP lifestyle intervention may themselves be at high risk for type 2 diabetes. To understand the potential reach of family-oriented diabetes prevention programming, we explored the correlation between parental eligibility for the National DPP program and child weight status by using nationally representative data.

\section{Methods}

We used data from the 2016 and 2017 National Health Interview Survey (NHIS), a nationally representative, annual survey of the noninstitutionalized United States population. ${ }^{10}$ The survey collects information ranging from sociodemographic characteristics to medical conditions, in addition to more in-depth information from 1 randomly selected sample adult and sample child per household. BMI information is available for children between the ages of 12 through 17, calculated based on weight and height reported by a household representative for the child. In 2016 and 2017, Diabetes Primary Prevention Questions, including those eliciting type 2 diabetes risk factors, were asked of sample adults.

Our study population consisted of children 12 through 17 years of age whose father or mother was selected as a sample adult (and therefore could be linked with the child). The sample was further restricted to children whose linked father or mother did not have a self-reported diagnosis of diabetes, was 18 years of age or older, and responded themselves (as opposed to having a proxy respondent) to sample adult questions. We excluded parents with a self-reported diagnosis of diabetes to focus on children with linked parents who were potentially eligible for diabetes prevention program participation. In the final sample, we also excluded children for whom child or parent BMI data were missing (in total $7.9 \%$ of children meeting inclusion criteria: $5.9 \%$ without child BMI data and $1.9 \%$ without parental BMI data).

\section{Child BMI Categorization}

We defined children as underweight/normal weight, overweight, or obese based on Centers for Disease Control and Prevention BMI-for-age charts, ${ }^{11}$ using standard percentile cut-offs for these categories (with overweight status defined as 85 th percentile to less than 95 th percentile of BMI-for-age, and obesity status defined as greater than or equal to 95 th percentile for age). Child age in the NHIS is expressed in years, whereas BMI-for-age is characterized by months; we used BMI cut-offs for the largest number of months corresponding to each year of age.

\section{Parental Diabetes Prevention Program Eligibility}

Parental diabetes prevention program eligibility was determined based on program eligibility criteria. ${ }^{9}$ Specifically, parents of 18 years and older who did not have a self-reported diagnosis of diabete, were considered eligible if they met (1) BMI criteria (BMI, $\geq 25 \mathrm{~kg} / \mathrm{m}^{2}$; or BMI, $\geq 23 \mathrm{~kg} / \mathrm{m}^{2}$ if Asian) and (2) had a self-reported diagnosis of prediabetes or history of gestational diabetes. A limited percentage of group participants can meet eligibility criteria by having high scores on risk assessments, such as the American Diabetes Association Diabetes Risk Test ${ }^{9}$ (in addition to meeting BMI crite- 
ria); we performed sensitivity analyses including these parents as eligible adults.

\section{Parental BMI Categorization}

Parental BMI was categorized as underweight/normal weight (BMI, $<25 \mathrm{~kg} / \mathrm{m}^{2}$ ), overweight (BMI, $\geq 25 \mathrm{~kg} / \mathrm{m}^{2}$ and $<30 \mathrm{~kg} / \mathrm{m}^{2}$ ), and obese (BMI, $\geq 30$ $\left.\mathrm{kg} / \mathrm{m}^{2}\right)$.

\section{Analyses}

Descriptive statistics were used to characterize the prevalence of overweight and obesity and parental diabetes prevention program eligibility. Pearson's $\chi^{2}$ analyses were used to explore differences in the distribution of child weight status over parental weight status and parental diabetes prevention program eligibility. All analyses took into account the NHIS's complex survey design; sampling weights were adjusted to reflect pooling of multiple years of data, as per NHIS guidelines. ${ }^{10}$

\section{Results}

Table 1 shows characteristics of children and their linked parents in the final sample (consisting of 3,905 unweighted or 13,633,334 weighted children). Overall, $64.4 \%$ of children meeting age eligibility criteria were linked to either a mother or father for whom sample adult data were available; of these children, ultimately $91.7 \%$ were included in the final sample (did not have missing child or parental BMI data). [Table 1]

A total of $13.9 \%$ of children were overweight, and $11.9 \%$ were classified as obese. The majority of parents were either overweight $(35.3 \%)$ or obese $(32.8 \%)$. A total of $9.5 \%$ of parents in the sample were likely eligible for diabetes prevention programming. Parent and child BMI were found to be correlated (Table 2; Pearson's $\chi^{2}, P<.001$ ), with more than one-fifth of children with obese parents being obese themselves, compared with only $5 \%$ of children with normal/underweight parents. A correlation between parental program eligibility and child BMI status was also noted (Table 3; Pearson's $\left.\chi^{2}, P<.001\right)$. Nearly 1 in $5(19.8 \%)$ children with a parent likely eligible for program participation was obese (Tables 2 and 3). In sensitivity analyses in which parental eligibility for diabetes prevention programming was expanded to include those who met alternate eligibility criteria (elevated BMI and
Table 1. Characteristics of Children and Linked Parents in the Analytic Sample*

\begin{tabular}{|c|c|}
\hline Characteristic & $\%($ of $\mathrm{N})$ \\
\hline \multicolumn{2}{|l|}{ Gender } \\
\hline Male & 49.9 \\
\hline Female & 50.1 \\
\hline \multicolumn{2}{|l|}{ BMI category } \\
\hline $\begin{array}{l}\text { Overweight }(\geq 85 \text { th percentile and }<95 \text { th } \\
\text { percentile BMI-for-age) }\end{array}$ & 13.9 \\
\hline Obese ( $\geq 95$ th percentile BMI-for-age) & 11.9 \\
\hline \multicolumn{2}{|l|}{ Parent gender } \\
\hline Male & 38.4 \\
\hline Female & 61.6 \\
\hline \multicolumn{2}{|l|}{ Parent BMI category } \\
\hline $\begin{array}{l}\text { Overweight (BMI, } \geq 25 \mathrm{~kg} / \mathrm{m}^{2} \text { and }<30 \\
\mathrm{~kg} / \mathrm{m}^{2} \text { ) }\end{array}$ & 35.3 \\
\hline Obese (BMI, $\left.\geq 30 \mathrm{~kg} / \mathrm{m}^{2}\right)$ & 32.8 \\
\hline Parent with prediabetes & 7.9 \\
\hline Mothers with history of gestational diabetes ${ }^{\dagger}$ & 9.7 \\
\hline $\begin{array}{l}\text { Parent likely eligible for diabetes prevention } \\
\text { programming }\end{array}$ & 9.5 \\
\hline
\end{tabular}

*Children ages 12 through 17 without missing BMI data, linked to parents who were sample adults, above the age of 18 , and did not report a history of diabetes and were not missing BMI data; $\mathrm{N}=13,633,334$ weighted children and linked parents.

${ }^{\dagger} \mathrm{N}=8,399,465$ weighted female parents.

${ }^{\ddagger}$ Based on meeting BMI criteria and having a diagnosis of prediabetes or history of gestational diabetes.

BMI, body mass index.

high American Diabetes Association Diabetes Risk Test scores), we saw similar patterns.

\section{Discussion}

In a national sample of children ages 12 through 17 years whose parents did not report a history of diabetes, a higher parental BMI was correlated with higher child BMI, and child overweight or obese status was positively correlated with parental eligibility for the National DPP lifestyle change program. These findings highlight the clustering of modifiable risk factors for type 2 diabetes and other lifestylerelated conditions, such as weight status, in families.

Family-level clustering of these factors, combined with evidence to support parental engagement as an essential component of childhood obesity program effectiveness, ${ }^{12}$ have informed the development of effective family-oriented obesity and diabetes prevention interventions for children. ${ }^{13-16}$ Rarely, however, have programs initially designed for adults been considered a means to reach high-risk children, either through spillover 
Table 2. Distribution of Child BMI by Parental BMI Categories*

\begin{tabular}{|c|c|c|c|c|}
\hline \multirow{3}{*}{ Child BMI Category } & \multicolumn{3}{|c|}{ Parental BMI Category } & \multirow{3}{*}{$P$ Value } \\
\hline & $\begin{array}{l}\text { Under/Normal } \\
\text { Weight } \\
(\mathrm{BMI},<25 \\
\left.\mathrm{kg} / \mathrm{m}^{2}\right)\end{array}$ & $\begin{array}{c}\text { Overweight } \\
\left(\mathrm{BMI}, \geq 25 \mathrm{~kg} / \mathrm{m}^{2} \text { and }\right. \\
\left.<30 \mathrm{~kg} / \mathrm{m}^{2}\right)\end{array}$ & $\begin{array}{c}\text { Obese } \\
\left(\mathrm{BMI}, \geq 30 \mathrm{~kg} / \mathrm{m}^{2}\right)\end{array}$ & \\
\hline & $\mathrm{N}=1,220^{\ddagger}$ & $\mathrm{N}=1,384^{\S}$ & $\mathrm{N}=1,301^{\|}$ & \\
\hline $\begin{array}{l}\text { Under/normal weight, \% (BMI-for-age } \\
<85 \text { th percentile) }\end{array}$ & 86.0 & 75.8 & 60.7 & $<.01$ \\
\hline $\begin{array}{l}\text { Overweight, } \% \text { (BMI-for-age } \geq 85 \text { th and } \\
<95 \text { th percentile) }\end{array}$ & 8.7 & 14.9 & 18.0 & \\
\hline Obese, $\%$ (BMI-for-age $\geq 95$ th percentile) & 5.3 & 9.3 & 21.2 & \\
\hline
\end{tabular}

*\% represents column distribution.

${ }^{\dagger}$ From Pearson's $\chi^{2}$ analysis.

${ }^{\ddagger I}$ nweighted N, representing 4,346,690 weighted individuals.

${ }^{\S}$ Unweighted $\mathrm{N}$, representing 4,815,587 weighted individuals.

$\|^{\$}$ Unweighted $\mathrm{N}$, representing $4,471,058$ weighted individuals.

BMI, body mass index.

effects of adult-oriented programming or familyoriented adaptations that intentionally address child health behaviors. There is, however, emerging and encouraging evidence to suggest that adaptations of the National DPP intervention that also address child health behaviors may be effective in improving children's weight trajectories. ${ }^{15}$

In this analysis, we were able to explore the relationship between only 1 parent and 1 child who were selected as sample household members. We do not have similar information for other parents or other children, in particular younger children, in the household. This may underestimate the percentage of children with parents eligible for diabetes prevention programming and could also impact evaluation of the correlation between parental and child BMI status, as the correlation between paren- tal BMI and child weight may vary with age. ${ }^{17,18}$ The use of self-reported (or proxy-reported in the case of children) weight and height data is also a limitation; self-reported data may lead to incorrect categorization of those particularly at extremes of BMI values, and studies suggest that parents often underestimate their child's weight status overall. ${ }^{19,20}$ In addition, BMI-for-age percentiles for children were determined based on age in years, not months, due to data limitations; we did assign percentiles based on the largest number of months corresponding to year of age as a more conservative definition of overweight or obesity. Another limitation in the evaluation of diabetes prevention program eligibility is the relatively low awareness of individuals with prediabetes; data suggests only 1 in 10 adults with prediabetes are aware

Table 3. Distribution of Child BMI Categories by Likely Parental Diabetes Prevention Program Eligibility*

\begin{tabular}{lcc}
\hline Child BMI Category & $\frac{\text { Parent Eligible }}{\mathrm{N}=356^{\dagger}}$ & Parent Ineligible \\
\cline { 2 - 3 } $\begin{array}{c}\text { Under/normal weight, \% (BMI-for-age } \\
\quad<85 \text { th percentile) }\end{array}$ & 65.6 & 75.2 \\
$\begin{array}{c}\text { Overweight, \% (BMI-for-age } \geq 85 \text { th and } \\
\quad<95 \text { th percentile) }\end{array}$ & 14.6 & 13.8 \\
Obese, \% (BMI-for-age $\geq 95$ th percentile) & 19.8 & 11.0 \\
\hline
\end{tabular}

*Eligibility determined by parental weight status and self-report of history of prediabetes or gestational diabetes; \% represents column distribution.

${ }^{\dagger}$ Unweighted $\mathrm{N}$, representing 1,297,367 weighted individuals.

${ }^{\ddagger}$ Unweighted N, representing 12,262,169 weighted individuals.

${ }^{\S}$ From Pearson's $\chi^{2}$ analysis.

BMI, body mass index. 
of their status. ${ }^{21}$ We did perform sensitivity analyses, including those with high diabetes risk scores, which revealed similar patterns.

We found that nearly 1 in 3 linked parents who were likely eligible for diabetes prevention programming had at least 1 child who was overweight or obese. This highlights the potential of family-oriented adaptations of programs targeting high-risk adults, such as the National DPP lifestyle intervention, to address risk factors among high-risk children. Family-oriented programming may also have a greater impact on both adults and children than individual-focused interventions and should be considered as 1 approach to reduce type 2 diabetes risk at the population level.

We had submitted this work as an abstract to the Society of General Internal Medicine's annual meeting (May 8-11, 2019), prior to acceptance of this manuscript to JABFM.

To see this article online, please go to: http://jabfm.org/content/ 32/4/596.full.

\section{References}

1. Mayer-Davis EJ, Lawrence JM, Dabelea D, et al. Incidence trends of type 1 and type 2 diabetes among youths, 2002-2012. N Engl J Med 2017;376:1419-29.

2. Imperatore G, Boyle JP, Thompson TJ, et al. Projections of type 1 and type 2 diabetes burden in the U.S. population aged $<20$ years through 2050: dynamic modeling of incidence, mortality, and population growth. Diabetes Care. 2012;35:2515-20.

3. Hamman RF, Wing RR, Edelstein SL, et al. Effect of weight loss with lifestyle intervention on risk of diabetes. Diabetes Care 2006;29:2102-7.

4. Diabetes Prevention Program (DPP) Research Group. The Diabetes Prevention Program (DPP): description of lifestyle intervention. Diabetes Care. 2002;25:2165-71.

5. Kumar S, Kelly AS. Review of childhood obesity: from epidemiology, etiology, and comorbidities to clinical assessment and treatment. Mayo Clin Proc 2017;92:251-65.

6. Liu Y, Chen H, Liang L, Wang Y. Parent-child resemblance in weight status and its correlates in the United States. PLoS One 2013;8:e65361.

7. Anderson PM, Butcher KF, Schanzenach DW. Childhood disadvantage and obesity: is nurture trumping nature? In: Gruber J, editor. The problems of disadvantaged youth: an economic perspective. Chicago: University of Chicago Press; 2009.

8. Pinhas-Hamiel O, Standiford D, Hamiel D, Dolan LM, Cohen R, Zeitler PS. The type 2 family: a setting for development and treatment of adolescent type 2 diabetes mellitus. Arch Pediatr Adolesc Med 1999;153:1063-7.

9. Centers for Disease Control. Centers for Disease Control and Prevention Diabetes Prevention Recognition Program. Standards and operating procedures. Available at: https://www.cdc.gov/diabetes/prevention/pdf/dprp-standards.pdf. Published March 1, 2018. Accessed September 24, 2018.

10. Centers for Disease Control and Prevention. Variance estimation Guidance, NHIS 2016. Available at: https:// www.cdc.gov/nchs/data/nhis/2016var.pdf. Published October, 2018. Accessed September 2, 2018.

11. Centers for Disease Control and Prevention National Center for Health Statistics. Growth charts: percentile data files with LMS values. Available at: https://www. cdc.gov/growthcharts/percentile data files.htm. Published August 4, 2009. Accessed September 24, 2018.

12. McLean N, Griffin S, Toney K, Hardeman W. Family involvement in weight control, weight maintenance and weight-loss interventions: a systematic review of randomized trials. Int J Obes Relat Metab Disord 2003;27:987-1005.

13. Golan M, Weizman A. Familial approach to the treatment of childhood obesity: conceptual model. J Nutr Educ 2001;33:102-7.

14. Burnet DL, Plaut AJ, Wolf SA, et al. Reach-out: a family-based diabetes prevention program for African American youth. J Natl Med Assoc 2011;103:269-77.

15. Hannon TS, Saha CK, Carroll AE, Palmer KH, O'Kelly Phillips E, Marrero DG. The ENCOURAGE healthy families study: a comparative effectiveness trial to reduce risk for type 2 diabetes in mothers and children. Pediatr Daibetes 2018;19:1041-9.

16. Jortberg BT, Rosen R, Roth S, et al. The fit family challenge: a primary care childhood obesity pilot intervention. J Am Board Fam Med 2016;29:434-43.

17. Svensson V, Jacobsson JA, Fredriksson R, et al. Associations between severity of obesity in childhood and adolescence, obesity onset and parental BMI: a longitudinal cohort study. Int J Obes 2011;35:46-52.

18. Botton J, Heude B, Maccario J, et al. Parental body size and early weight and height growth velocities in their offspring. Early Hum Dev 2010;86:445-50.

19. Stommel M, Schoenberon CA. Accuracy and usefulness of BMI measures based on self-reported weight and height: findings from the NHANES \& NHIS 2001-2006. BMC Public Health 2009;9:421.

20. Lundahl A, Kidwell KM, Nelson TD. Parental underestimates of child weight: a meta-analysis. Pediatrics. 2014;133:e689-e703.

21. Centers for Disease Control and Prevention. National Diabetes Statistics Report: estimates of diabetes and its burden in the United States, 2017. Atlanta, GA: US Department of Health and Human Services; 2017 Available at: https://www.cdc.gov/diabetes/pdfs/data/ statistics/national-diabetes-statistics-report.pdf. Accessed October 21, 2018. 